\title{
Article \\ Effects of Weir Operation on Seasonal Groundwater Use: A Case Study of the Han River, South Korea
}

\author{
Hyeonju Lee ${ }^{1}\left(\mathbb{D}\right.$, Eunhee Lee ${ }^{1}$, Yongcheol Kim ${ }^{1}$, Soo-Hyoung Lee ${ }^{1}$ and Min-Ho Koo ${ }^{2, *(D)}$ \\ 1 Groundwater Environment Research Center, Climate Change Response Division, Korea Institute of \\ Geoscience and Mineral Resources, Daejeon 34132, Korea; hjlee@kigam.re.kr (H.L.); \\ eunheelee@kigam.re.kr (E.L.); yckim@kigam.re.kr (Y.K.); rbagio@kigam.re.kr (S.-H.L.) \\ 2 Department of Geoenvironmental Sciences, Kongju National University, Kongju 32588, Korea \\ * Correspondence: koo@kongju.ac.kr; Tel.: +82-41-850-8515
}

check for updates

Citation: Lee, H.; Lee, E.; Kim, Y.; Lee, S.-H.; Koo, M.-H. Effects of Weir Operation on Seasonal Groundwater Use: A Case Study of the Han River, South Korea. Water 2022, 14, 646. https://doi.org/10.3390/w14040646 Academic Editor: Andrzej Witkowskı

Received: 11 January 2022 Accepted: 15 February 2022 Published: 18 February 2022

Publisher's Note: MDPI stays neutral with regard to jurisdictional claims in published maps and institutional affiliations.

Copyright: (C) 2022 by the authors. Licensee MDPI, Basel, Switzerland. This article is an open access article distributed under the terms and conditions of the Creative Commons Attribution (CC BY) license (https:// creativecommons.org/licenses/by/ $4.0 /)$.

\begin{abstract}
During the cold dry season, a large amount of groundwater is pumped for water-curtain cultivation in agricultural fields mostly located near the four major rivers of South Korea. Several weirs, installed previously to secure sufficient water resources from these rivers, were opened in 2017 for restoring the riverine environment. Weir-controlled river level fluctuations have altered stream-aquifer interactions, leading to groundwater drawdown. In this study, changes in streamaquifer interaction caused by seasonal pumping and weir opening were investigated, using Visual MODFLOW. Two indexes that considered the pump type and aquifer characteristics-the pumping available thickness (PAT) and aquifer productivity index (API)—were used to analyze the effects of weir opening on seasonal groundwater use. Our simulations indicated that weir opening had a large impact on seasonal groundwater use due to groundwater drawdown, especially with respect to centrifugal pumps located in low transmissivity areas where the API decreased after the weir was opened. The resulting decrease in groundwater pumping rates would lower the thermal effect of the water-curtain greenhouse process. This indicates that water supply alternatives are needed so that the weirs can be operated efficiently and field requirements can be met, while the deleterious effects on groundwater are avoided.
\end{abstract}

Keywords: Ipo Weir; weir operation; seasonal groundwater use; stream-aquifer interaction; MODFLOW

\section{Introduction}

In South Korea, a significant amount of groundwater is used in many agricultural areas for 'water-curtain cultivation' during the cold winters. This is a facility cultivation technique, whereby relatively warm groundwater is sprayed onto greenhouse roofs for heating during the cold season. Water-curtain cultivation is mostly practiced in alluvial areas near the four major rivers, which have abundant groundwater resources. The areas involved in water-curtain cultivation have expanded recently from $39.71 \mathrm{~km}^{2}$ in 2010 to $74.09 \mathrm{~km}^{2}$ by 2017, representing an increase of approximately 87\% [1]. Water-curtain cultivation comes in two forms: circulating and non-circulating systems. Non-circulating systems, which were employed in $72 \%$ of the total area under water-curtain cultivation in 2017 , are mostly used in agricultural fields where the groundwater used for greenhouse heating is discharged into nearby streams [2]. Water-curtain cultivation is a useful technology which replaces the need for oil energy and brings significant economic benefits. However, it uses a lot of groundwater during the cold dry season, perhaps exceeding aquifer recharge capacity [3]. For example, the annual precipitation recharge is only $11 \%$ of the total groundwater withdrawal in large agricultural fields of Miryang [4]. This could lead to long-term groundwater depletion along with associated changes to the riverine environment [4,5]. River flows can also be affected by changes in stream-aquifer interactions in cases where they depend on groundwater discharge [6,7]. 
Groundwater in the agricultural areas has been affected by weir construction and river maintenance. Sixteen weirs were constructed in the four major rivers in 2012, affecting both the river environments and nearby groundwater flows, particularly in areas where many water-curtain greenhouse facilities were located. Numerous studies have been conducted on the impacts of weir construction on stream-aquifer interactions. The increased river levels caused by weir construction increased nearby groundwater levels, resulting in abundant water resources; in some areas groundwater flooding has been reported [8,9]. The presence of the weirs also decreased the seasonal influence of rainfall on river flows. It prevented flooding during the wet season and increased river flows during the dry season [10,11]. The associated river environment changes also affected groundwater flow and quality, owing to stream-aquifer interactions, which in turn affected groundwater use near the river [12,13].

It was found that restricting river flows deteriorated river water quality, adversely affecting the river ecosystem $[14,15]$. In response to this, nine weirs have been opened since 2017 to improve river water quality and restore aquatic ecosystems. The rivers and aquifers were monitored to assess the impact of these openings, and it was found that the increased river flows improved the water quality and environmental conditions [16,17], whereas water levels in the upstream rivers decreased. These river level declines reduced groundwater levels, and as a result, groundwater yield was also affected in some areas [18,19]. These decreased groundwater pumping rates led to some crops suffering cold damage as watercurtain greenhouse temperatures became lower in winter. In anticipation of these issues, several studies assessed how opening of the weir would affect stream-aquifer interactions, although few looked into groundwater use during the dry season $[17,20]$.

This study aims to investigate the effect of weir operation on the stream-aquifer interactions and seasonal groundwater use for water-curtain cultivation. In this work, Yeoju greenhouse cultivation area on the riverside upstream of Ipo Weir was studied, and changes in groundwater flow and storage caused by seasonal pumping and weir operation were analyzed using Visual MODFLOW Classic (Waterloo Hydrogeologic Inc., v. 4.6.0.169, Waterloo, ON, Canada), which is a three-dimensional (3-D) finite difference model. This study considered the cases of a management level (closure of the water gate) and a minimum level (opening of the water gate) of the Ipo Weir. We also analyzed the impacts of weir operation on groundwater pumping rate and seasonal groundwater use, using two indexes that considered the pump type and aquifer characteristics. The results of this study will be helpful in establishing efficient water resource management plans by quantitatively evaluating the effects of weir opening on seasonal groundwater use. In addition, the methodology demonstrated in this study can also provide a basis for further quantifying stream-aquifer interactions affected by anthropogenic activities in other agricultural areas.

\section{Materials and Methods}

\subsection{Study Area and Hydrogeological Setting}

The study area was located on a $2.1 \mathrm{~km}^{2}$ alluvial aquifer of the Han River, in Yeoju, South Korea (Figure 1), on the plains between $127.570-127.591^{\circ} \mathrm{E}$ and $37.352-37.370^{\circ}$ $\mathrm{N}$ surrounded by mountains. This area was selected as one where the groundwater is greatly affected by river fluctuations due to the opening of the weir, as it is located on the riverside upstream of the weir. Average rainfall and temperature measured from 1985 to 2014 were $1336 \mathrm{~mm}$ /year and $11.6^{\circ} \mathrm{C}$, respectively. Seasonal variations of rainfall range from $15 \mathrm{~mm} /$ year in February (dry season) to $402 \mathrm{~mm} /$ year in July (wet season) [21]. The Han River flows from south to west in the southwestern part of the study area, where its width varies from $300-800 \mathrm{~m}$, and it is approximately $4 \mathrm{~m}$ deep on average [22]. Ipo Weir is located downstream of the study area, and it has a management level of $28 \mathrm{~m}$. The Goksucheon, a tributary of the Han River, is located in the northern part of the study area. The tributary, with a width of about $45 \mathrm{~m}$ near the study area, originates in the mountains located in the hinterland and is discharged into the Han River. The local bedrock consists 
predominantly of Jurassic igneous rocks, and the sediments in the site consist of Quaternary alluvium which unconformably overlie the bedrock. This alluvium was deposited in a fluvial environment and is generally distributed along the Han River and its tributaries.
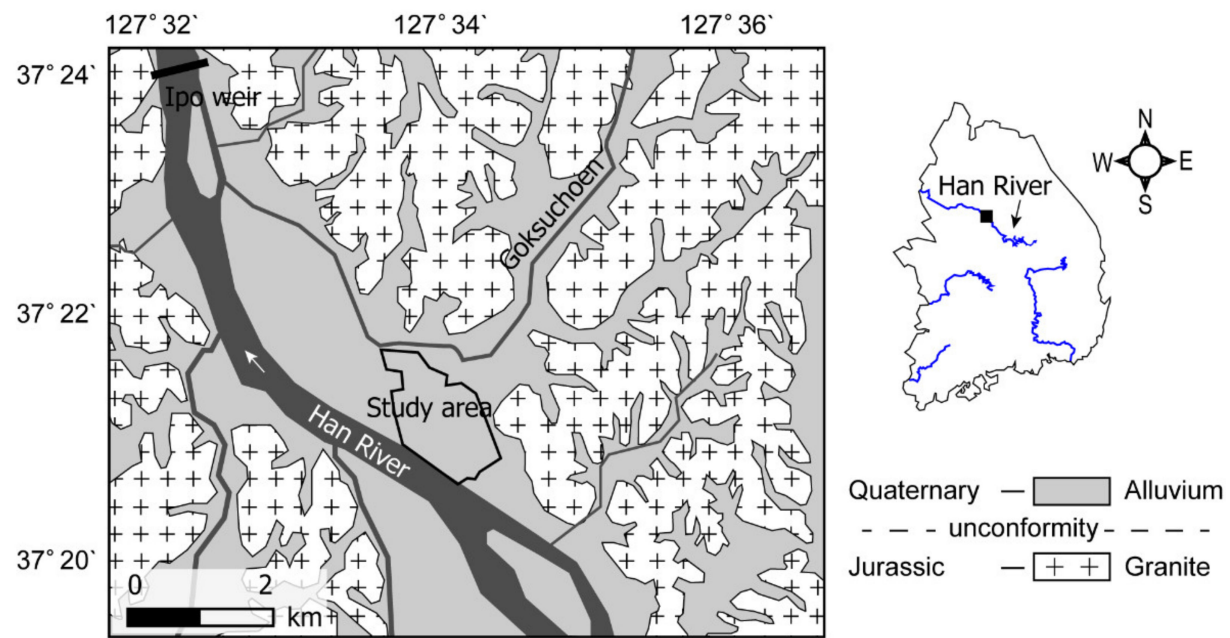

Figure 1. Location and geology of the study area in Han River Basin, South Korea (modified from [23]).

The sedimentary structure of the alluvial deposits can be seen in Figure 2. Columnar sections of the three monitoring wells located in the study area were used to analyze sedimentary layer distribution (Figure 2a). We found that the alluvium was composed of silty sand and weathered soil (Figure $2 b$ ). The surface elevation at the site varied from 36-43 m, average thickness of the silty sand layer was $13.5 \mathrm{~m}$, and the weathered soil layer was $1.5 \mathrm{~m}$ thick. Groundwater was located in the silty sand layer, which was connected to the river.
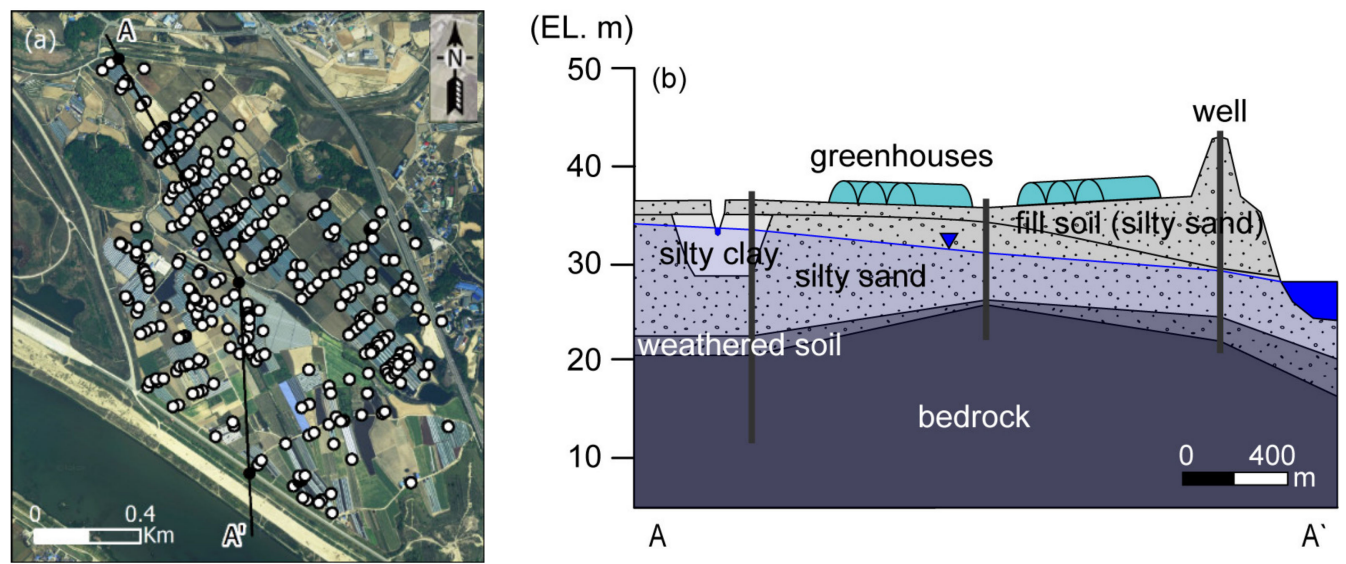

Figure 2. (a) Location of pumping wells with cross-section line and (b) generalized geological crosssection showing sedimentary structure of the alluvial deposits analyzed using columnar sections of the three monitoring wells (black lines).

The study area was characterized by greenhouse cultivation areas, which produce crops of sweet potato, cucumber, eggplant, and pumpkin using the water-curtain cultivation technique during winter. Out of the 348 pumping wells in the study area, we found that 273 were used for water-curtain cultivation (Figure 2a). Centrifugal pumps that pull water up from the land surface and underwater pumps that are used submerged in the well were installed in 93 and 252 pumping wells, respectively (with 3 unidentified wells). The study area was considered to be a typical representative of water-curtain greenhouse cultivation areas near rivers in South Korea. 


\subsection{Numerical Model}

Groundwater flow steady-state simulations were carried out using Visual MODFLOW, a 3-D finite-difference flow model to analyze changes in stream-aquifer interaction following the opening of the weir. The study area is close to $1.4 \mathrm{~km}$ from the river and shows a relatively high transmissivity of $642 \mathrm{~m}^{2} /$ day compared to the average value of South Korea as a result of the groundwater pumping test [24,25], which means that a new equilibrium state is quickly reached after a hydraulic stress is applied [26,27]. Therefore, the steadystate simulations were performed to simplify the model and compare the stream-aquifer interactions in an equilibrium state before and after the weir operation.

Figure 3 shows the model domain, in which a $20 \times 20 \mathrm{~m}$ grid was used, covering a $7.8 \times 6.4 \mathrm{~km}$ area divided into 320 rows and 390 columns. Figure 3a,b show the boundary conditions and spatial distribution of model properties (hydraulic conductivity), respectively. The model domain was designed to include adjacent areas with similar sedimentary structures, because of a scarcity of field data, and topographic limits of hinterland, to minimize boundary uncertainty, including the study area. The sedimentary structure of the alluvial deposits was reflected in the model by applying columnar section data from eight monitoring wells. The model was discretized vertically into three layers, with the upper layer consisting of silty sand, the second layer made up of weathered soil, and the lower layer composed of granite (Figure 2). The top surface elevation of the model was assigned using a digital elevation model (DEM) with the columnar section data, and the bottom elevation of the lower layer was set at a constant $0 \mathrm{~m}$.
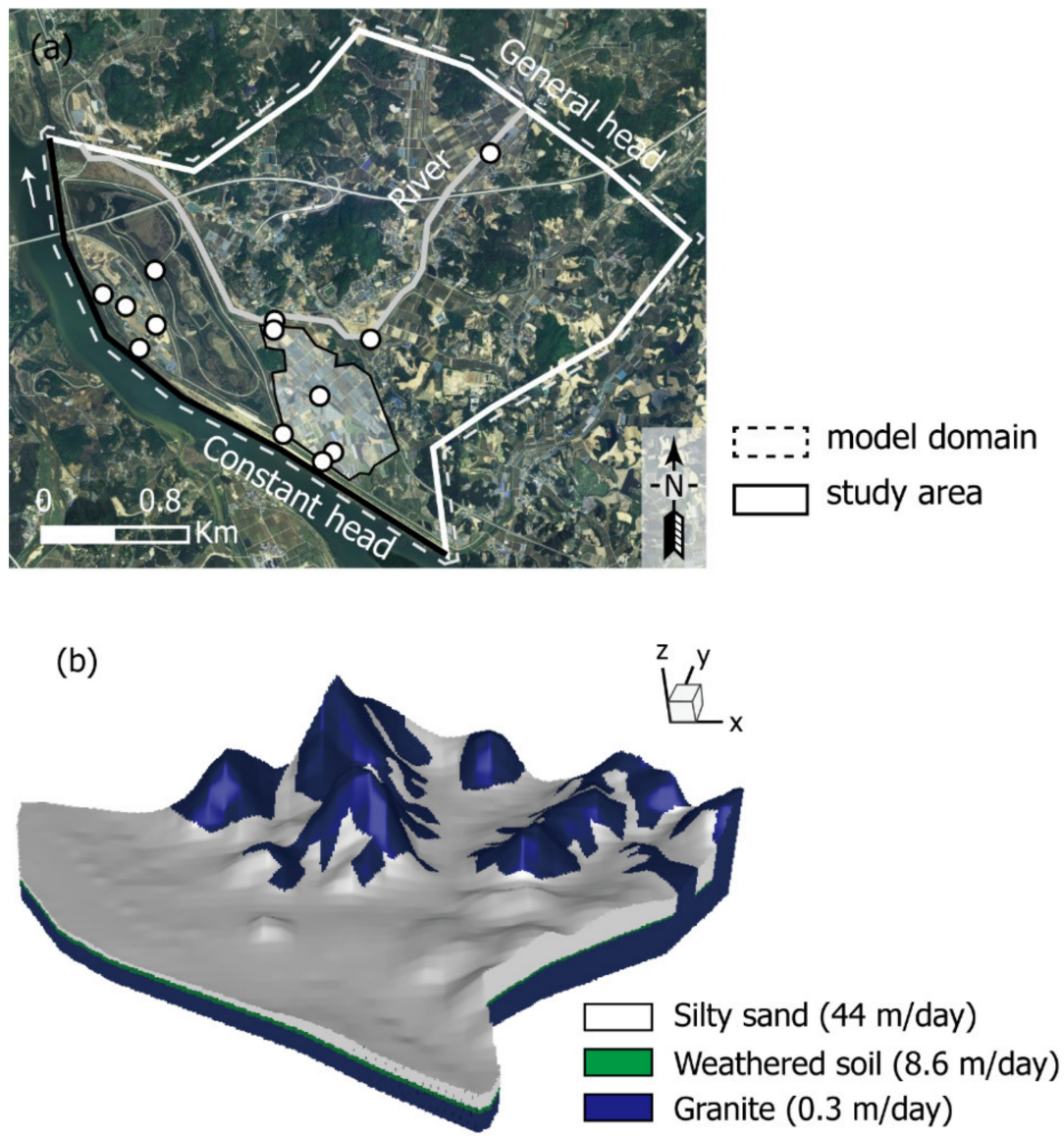

Figure 3. (a) Conceptual model showing boundary conditions and locations of 13 monitoring wells (circles) with the study area near the river (polygon) and (b) spatial distribution of hydraulic conductivity. 
The Han River was represented as constant head boundary (Dirichlet condition) because the water level remains constant due to the management level of the weir, and the riverbed and aquifer are well connected (Figure 3a). River levels were set to either the Ipo Weir management level $(28 \mathrm{~m})$ or minimum level $(25.3 \mathrm{~m})$. The Goksucheon tributary was set as an upper layer river boundary (Cauchy condition) in order to reflect the small rivers where river flow is affected by rainfall. In the river boundary, water flows in direct proportion to the head difference between the river and groundwater levels, and a certain amount of river water flows into the aquifer when the groundwater level is lower than the riverbed. Its water levels were set to values between $27.5-41.0 \mathrm{~m}$, considering both the observed river level and surface altitude, and the river depth was set to $0.5 \mathrm{~m}$. The hinterland was represented by a general head boundary (Cauchy condition) to represent groundwater inflow from mountainous areas, and conductance of both the riverbed and the hinterland were calibrated. In this boundary condition, like the groundwater flow in a high mountain, an infinite flow occurs in proportion to the water level difference with the surrounding groundwater level. Water levels of the general head boundary were set to values between $28.5-50.0 \mathrm{~m}$, considering both the surface altitude and groundwater level contour map estimated by kriging with observation data in 2015, when the only observation data for the hinterland exists [21]. The groundwater recharge rate, which was calculated using average precipitation $(1336 \mathrm{~mm}$ /year) and recharge factor (0.19) data for the study area [21], was set at $258 \mathrm{~mm} /$ year and was applied to the top layer of the model. The hydraulic conductivity of the upper layer, which was estimated using a pumping test [24], was set to $44 \mathrm{~m} /$ day, while the hydraulic conductivities of the second and lower layers were calibrated (Figure $3 b$ ).

There were 819 pumping wells in the model domain, which were classified based on their use. Out of the wells, 583 were for agricultural use, 223 for living, and 13 for other uses. Daily pumping rates were calculated using the equations for estimating groundwater use according to the purpose of use, which is presented in [28], and annual groundwater use in 2018 [29]. The estimated total pumping rates were $886 \mathrm{~m}^{3} /$ day for agricultural use, $258 \mathrm{~m}^{3}$ /day for living, and $227 \mathrm{~m}^{3}$ /day for other uses, as noted in Table 1 . During the seasonal pumping period, the daily pumping rate for each water-curtain cultivation was set to $15 \mathrm{~m}^{3}$ / day for 372 groundwater pumping wells out of the 431 wells used for gardening. This pumping rate for water-curtain cultivation was estimated using the average yearly groundwater use by each water-curtain greenhouse $\left(62 \mathrm{~m}^{3} /\right.$ day $)$ [30] and the pumping period (90 days).

Table 1. Estimated groundwater pumping rates $\left(\mathrm{m}^{3} /\right.$ day).

\begin{tabular}{|c|c|c|c|c|c|}
\hline \multicolumn{2}{|c|}{ Classification } & \multirow{2}{*}{$\begin{array}{c}\begin{array}{c}\text { Number of } \\
\text { Wells }\end{array} \\
73\end{array}$} & \multirow{2}{*}{$\begin{array}{c}\begin{array}{c}\text { Pumping } \\
\text { Rates }\end{array} \\
447\end{array}$} & \multicolumn{2}{|c|}{ Total Pumping Rates } \\
\hline \multirow{3}{*}{ Agricultural use } & $\begin{array}{l}\text { Field crop } \\
\text { (non-rice) }\end{array}$ & & & \multirow{3}{*}{\multicolumn{2}{|c|}{886}} \\
\hline & Rice field & 79 & 250 & & \\
\hline & Gardening & 431 & 189 & & \\
\hline \multirow{3}{*}{ Living } & Household & 200 & 160 & \multirow{3}{*}{258} & \multirow{5}{*}{1371} \\
\hline & General purpose & 22 & 86 & & \\
\hline & School & 1 & 12 & & \\
\hline \multirow{2}{*}{ Other uses } & Industrial use & 6 & 192 & \multirow{2}{*}{227} & \\
\hline & Others & 7 & 35 & & \\
\hline
\end{tabular}

The model was calibrated using trial and error, with model parameters adjusted until the fit between model outputs and observations was acceptable. Calibration involved changing hydraulic conductivity input values for the weathered and bedrock layers (second and lower layers), and the conductance of the hinterland and Goksucheon tributary. 
Calibration was achieved by matching the calculated heads with groundwater data obtained from 13 monitoring wells when the river level was at the management level of the Ipo Weir (Figure 3a). Average annual groundwater levels from 5 wells out of the 13 wells were used, while the average value observed in August 2019 was used for the groundwater level in 8 wells out of the 13 wells because of the lack of observation data.

Several trial and error simulations revealed that an acceptable fit was obtained between the observed and simulated heads when the hydraulic conductivity values were $8.6 \mathrm{~m} /$ day for the weathered layer (second layer) and $0.3 \mathrm{~m} /$ day for the bedrock (lower layer) (Table 2). The final calibrated hinterland conductances were $20 \mathrm{~m}^{2} /$ day and $50 \mathrm{~m}^{2} /$ day for the bedrock and alluvium, respectively, while the calibrated conductance of the Goksucheon was $10 \mathrm{~m}^{2} /$ day. The agreement between the calculated and measured heads and the distribution of the calculated groundwater levels can be seen in Figure 4. The root mean square error (RMSE) and the normalized root mean square error (NRMSE) between the observed and calculated heads were $0.88 \mathrm{~m}$ and $6.3 \%$ (Figure $4 \mathrm{a}$ ), respectively, which indicates that the simulated heads matched the observed values reasonably well [31]. Average annual groundwater level showed groundwater was introduced from the hinterland and discharged into the river, showing a distribution similar to the observation data (Figure $4 \mathrm{~b}$ ).

Table 2. Hydraulic parameter values used in the model.

\begin{tabular}{ccccc}
\hline \multicolumn{4}{c}{ Alluvium } & \\
\hline & Upper Unit & Middle Unit & Bedrock & Riverbed \\
\hline $\begin{array}{c}\text { Hydraulic conductivity } \\
(\mathrm{m} / \text { day })\end{array}$ & 44 & 8.6 & 0.3 & - \\
\hline $\begin{array}{c}\text { Conductance of } \\
\text { boundary }\left(\mathrm{m}^{2} / \text { day }\right)\end{array}$ & 50 & 20 & 10 \\
\hline
\end{tabular}

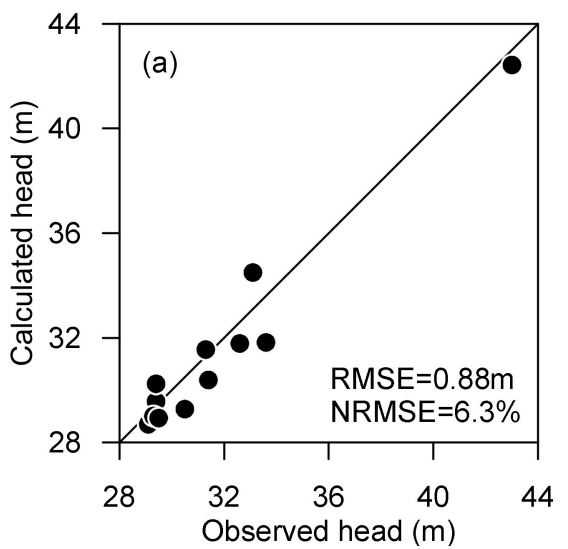

(b)

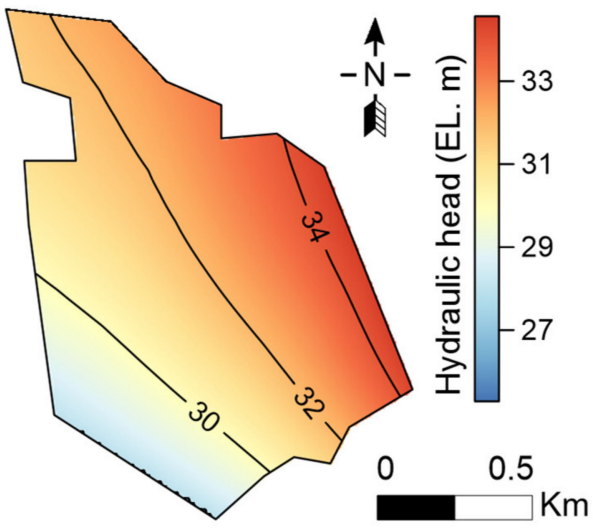

Figure 4. Calibration results: (a) comparisons between calculated and measured groundwater levels; (b) calculated groundwater level distributions.

\subsection{Pumping Available Thickness and Aquifer Productivity Index}

Groundwater levels were analyzed to investigate changes in the groundwater flow system caused by seasonal pumping for water-curtain cultivation and weir operations. Areas in which crop cultivation was affected by decreased groundwater pumping rates were analyzed using predicted groundwater levels. Two indexes that considered pump type and aquifer characteristics-pumping available thickness (PAT) and aquifer productivity index (API) - were used to analyze the effects of the opening of the weir on groundwater pumping from the wells.

In centrifugal pumps, groundwater from depths of up to $8 \mathrm{~m}$ can be pumped, depending on the suction height capability of the pump. Therefore, groundwater depth from the surface can be used to evaluate the impact of opening the weir on groundwater use 
in centrifugal pumps. In this study, the minimum PAT from the water table to the critical depth $(8 \mathrm{~m})$ was assumed to be $1 \mathrm{~m}$, considering not only the greatest decrease in well water levels due to the cone of depression, but also well loss. In other words, groundwater was considered to be depleted, and could not be pumped by centrifugal pumps, if the PAT values were less than $1 \mathrm{~m}$. The PAT values were calculated using the groundwater level estimated in the model.

In addition, because specific capacity decreases in proportion to transmissivity, the API was applied to show how groundwater pumping rates relatively decreased after opening the weir. The API was calculated as follows:

$$
\mathrm{API}=\frac{T_{2}}{T_{1}}
$$

where $T_{1}$ and $T_{2}$ stand for transmissivities before and after opening the weir, respectively. The model assumes that crop cultivation will be damaged due to decreased groundwater pumping rates if the API decreases to 0.8 , considering the cone of depression in the wells. This meant that the specific capacity was reduced by $20 \%$ owing to the opening of the weir, although actual well pumping rates varied greatly depending on the performance characteristics of individual pumps. The API values were calculated using the hydraulic conductivity of each layer and the groundwater level estimated in the model.

\section{Results and Discussion}

\subsection{Impacts of Opening of the Weir on Stream-Aquifer Interactions}

Our model results showed that water level fluctuations played an important role in stream-aquifer interactions, which is consistent with the previous research results [32,33]. Figures 5 and 6 show the spatial variations in groundwater levels and drawdown resulting from opening the weir, which were presented by kriging with calculated values from calibrated model. During the non-seasonal pumping period (Figure 5), the groundwater level was higher than the river level, showing a gaining stream (Figure 5a), while once the river level decreased, the groundwater level fell near the river by approximately 2.7 $\mathrm{m}$ (Figure 5b). This groundwater drawdown decreased with distance from the river (Figure 5c).

(a)



(b)

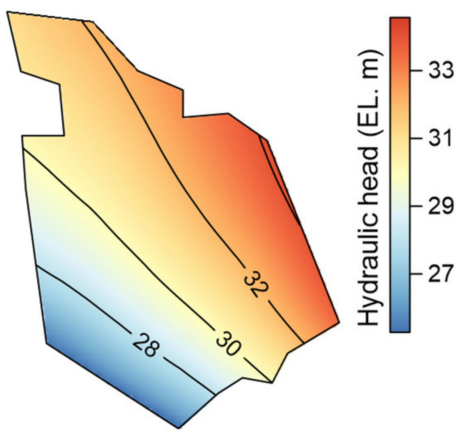

(c)

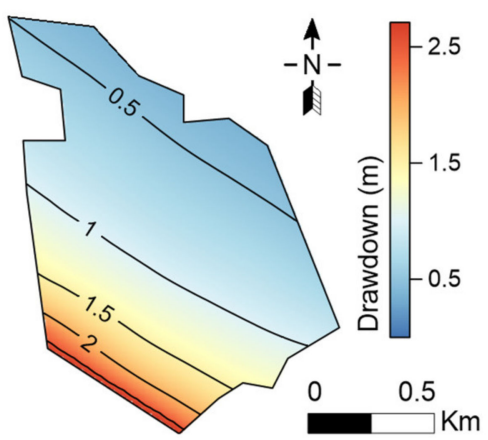

Figure 5. Changes in calculated groundwater levels due to opening of the weir during the nonseasonal pumping period, when the river level is (a) at the Ipo Weir management level (28 m), (b) at the minimum weir level $(25.3 \mathrm{~m})$, and (c) groundwater drawdown. 
(a)

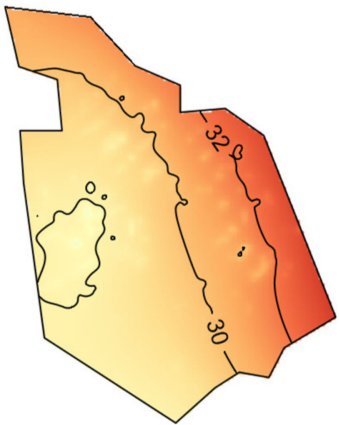

(b)

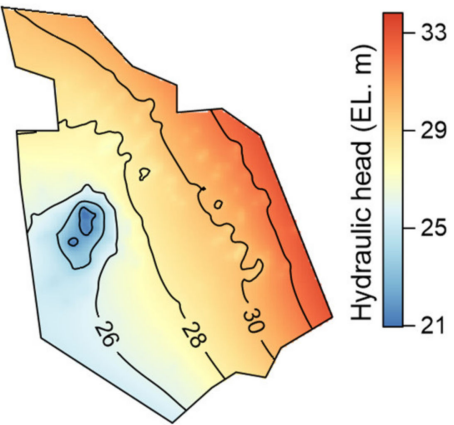

(c)

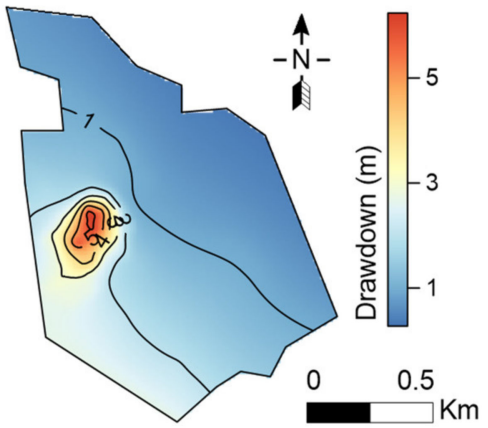

Figure 6. Changes in calculated groundwater levels due to opening of the weir during the seasonal pumping period, when the river level is (a) at the Ipo Weir management level $(28 \mathrm{~m}),(\mathbf{b})$ at the minimum weir level $(25.3 \mathrm{~m})$, and (c) groundwater drawdown.

During the seasonal pumping period (Figure 6), the groundwater level fell and cones of depression formed in areas where there were numerous groundwater pumping wells used for water-curtain cultivation (Figure 6a). In these depression areas, the groundwater level decreased below the weathered soil layer after the opening of the weir, which means that transmissivity also decreased (Figure $6 \mathrm{~b}, \mathrm{c}$ ). Overall, we were able to conclude that changes in river level due to the opening of the weir had a greater impact during the seasonal pumping period, because the groundwater levels changed even more when the effect of groundwater pumping and river level decline were combined.

The simulated water balance indicated that, after the river level had decreased, groundwater discharge from the aquifer to the Han River increased by $72 \%$, while discharge to the tributary decreased by $4 \%$. In winter, groundwater pumping accounted for $72 \%$ of the total groundwater recharge, and the opening of the weir increased the groundwater discharge to the Han River by $30 \%$. The hydrological condition of the tributary changed from a gaining to a losing stream, which could have strongly affected the quantity and quality of both groundwater and tributary surface water [34-36].

\subsection{Changes in Groundwater Pumping Rate}

Groundwater storage losses can affect groundwater use, with the impact depending on the type of pump used. Groundwater pumping rate changes due to the API depend on the performance characteristics of the pump, and it can be seen in Figure 7 how the pump system curve changed with declining groundwater level after opening the weir. The figure also shows the head generated by the pump over a range of pumping rates, including its efficiency and brake horsepower [37]. The pump system curve depicts the relationship between the head pressure and pumping rates for an actual pump [38].

In the figure, it can be seen that the system curve (operation point) moves up with declining groundwater level $\left(\Delta H_{W}\right)$ after opening the weir $(\mathbf{0})$; consequently, the groundwater pumping rates decrease. The magnitude of decrease in transmissivity with groundwater drawdown increases the system curve inclination (2), decreasing pumping rates.

As groundwater drawdown is proportional to groundwater pumping rates, the system curve for the actual lift shows a linear change. However, groundwater pumping rates in actual wells increase nonlinearly with the head pressure due to frictional head losses. The inclination of the system curve, that is, the ratio of pumping rates and groundwater drawdown, decreases with aquifer productivity, that is, transmissivity. The intersection point between the pump performance curve and pump system curve is the operation point, which determines the pumping rate and groundwater level. 


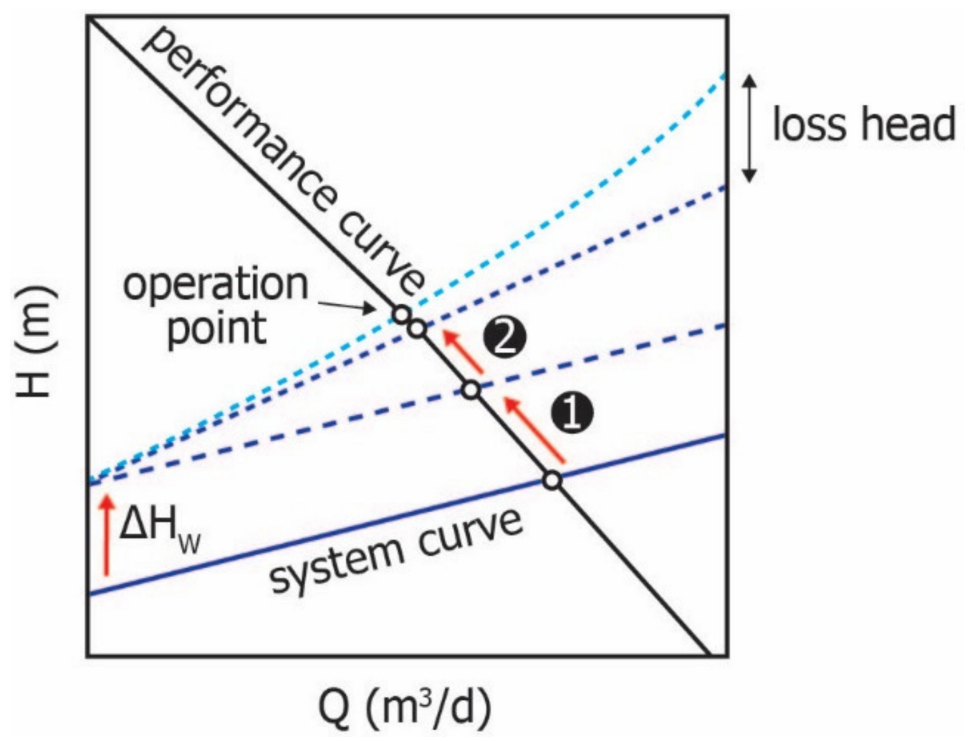

Figure 7. Change in the pump system curve owing to the decline in groundwater level (1)), decrease in transmissivity (2) experienced after opening the weir, and frictional head losses (sky blue dashed line).

Figure 8 shows how groundwater pumping rate changed depending on the type of pump with declining groundwater level after opening the weir. Figure 8a includes performance curves for centrifugal (PH-750W (HANIL Electric Co, Bucheon, Korea)) and underwater (SR4M-0322 (HANIL Electric Co, Bucheon, Korea)) pumps and Figure 8b illustrated pumping rate changes caused by the groundwater drawdown that followed the opening of the weir; they show how the groundwater pumping rates decreased as the groundwater level declined due to opening of the weir, without a change in API (API = 1). With decreasing groundwater level, the pumping rates achieved by centrifugal pumps decreased by a greater magnitude than those achieved by underwater pumps (Figure 8a). It can be seen that the drawdown caused the rates to decrease linearly (Figure $8 \mathrm{~b}$ ). The pumping rates achieved by the centrifugal and underwater pumps decreased by $16 \%$ and $2 \%\left(\mathrm{Q} / \mathrm{Q}_{0}=0.86\right.$ and 0.98$)$, respectively, after the groundwater level decreased by $8 \mathrm{~m}$, following the opening of the weir.

Figure $8 \mathrm{c}, \mathrm{d}$ show the difference in groundwater pumping rates between the centrifugal pump and underwater pump, with API changes caused when the groundwater level decreased by $4 \mathrm{~m}$ after opening the weir. The smaller the transmissivity, the lower the groundwater pumping rate. In the aquifer with a transmissivity of $10 \mathrm{~m}^{2} /$ day, the groundwater pumping rates achieved by the centrifugal pump decreased by $43 \%$ compared to those before the weir was opened when the API decreased to 0.2 (Figure 8c). On the other hand, the pumping rates achieved by the underwater pump decreased by just $12 \%$ under the same conditions (Figure $8 \mathrm{~d}$ ). Consequently, we could see that groundwater would deplete more in areas where centrifugal pumps were used and the transmissivities were low after the decline in groundwater levels and the API due to the opening of the weir. 

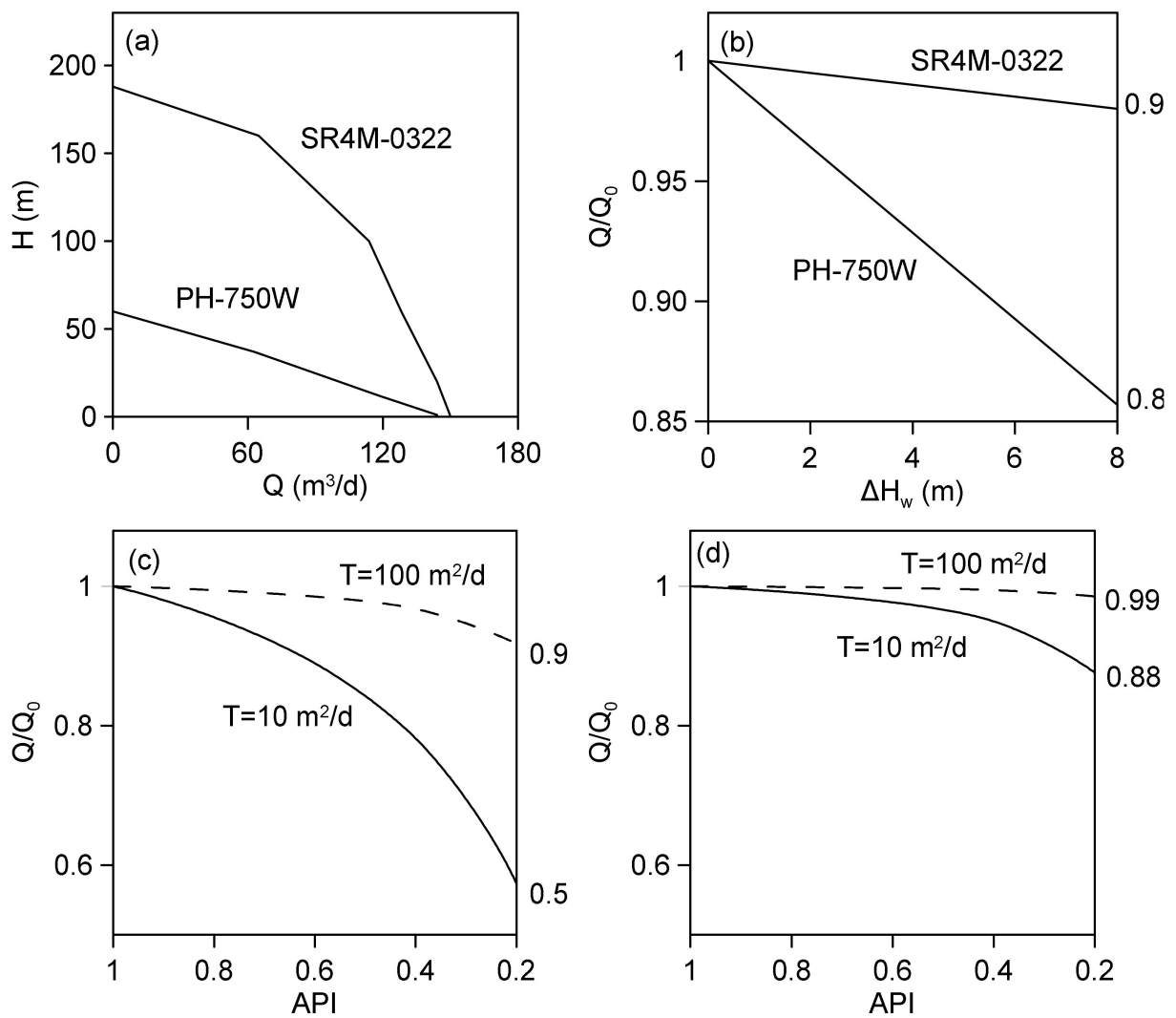

Figure 8. (a) Pump performance curves for centrifugal-type (PH-750W) and underwater-type (SR4M0322) pumps; changes in pumping rates due to the decline in groundwater level after opening the weir: (b) without a change in API (API = 1); and due to a decreased API at (c) the centrifugal pump, and (d) the underwater pump.

\subsection{Effects of Opening of the Weir on Seasonal Groundwater Use}

The areas in which groundwater pumping was difficult using centrifugal pumps were analyzed with respect to the PAT value, and the modeling results obtained when spatial and temporal PAT value variations were applied can be seen in Figure 9. During non-seasonal pumping period, the groundwater could not be accessed by centrifugal pumps in high surface altitude areas at the management level of the Ipo Weir (Figure 9a). The depletion area increased from 0.13 to $0.29 \mathrm{~km}^{2}$ after opening the weir, and the number of depleted wells increased from 7 to 12 out of the 93 applicable wells in the study area (Table 3 and Figure 9b).

Table 3. Number of centrifugal pumps that became ineffective due to the opening of the weir $(\mathrm{PAT} \leq 1)$.

\begin{tabular}{cccc}
\hline \multicolumn{2}{c}{ River Water Level (m) } & Area $\left.\mathbf{( k m}^{\mathbf{2}}\right)$ & $\begin{array}{c}\text { Number of } \\
\text { Centrifugal Pumps }\end{array}$ \\
\hline $\begin{array}{c}\text { Non-seasonal } \\
\text { pumping period }\end{array}$ & 28 & 0.13 & 7 \\
\hline \multirow{2}{*}{$\begin{array}{c}\text { Seasonal } \\
\text { pumping period }\end{array}$} & 25.3 & 0.29 & 12 \\
\hline
\end{tabular}



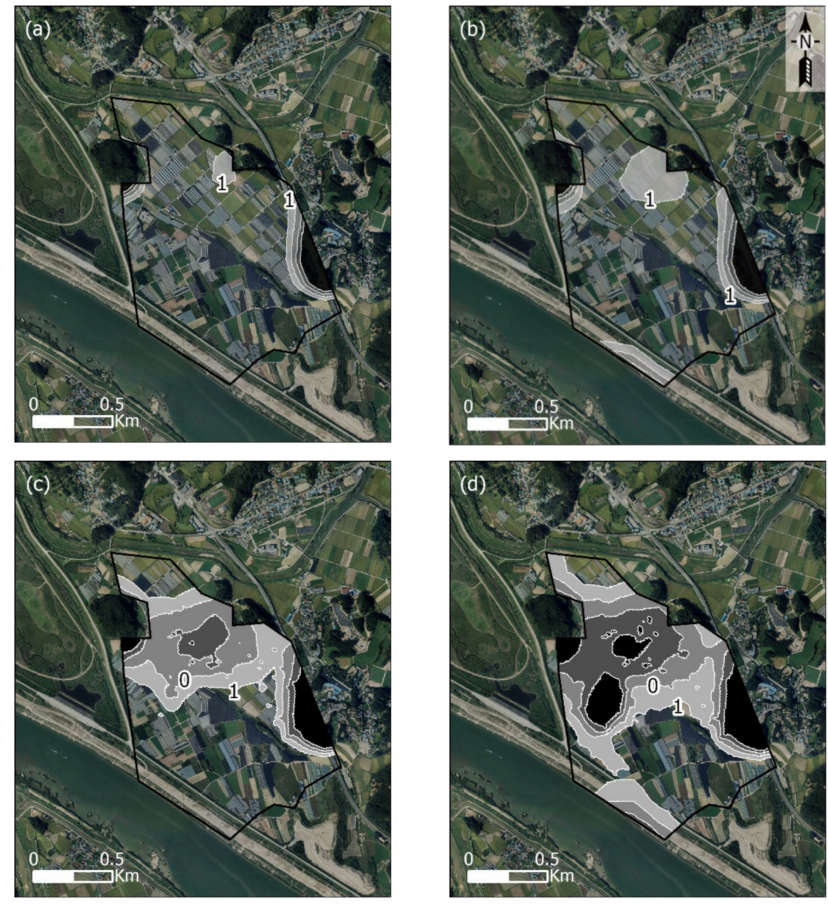

Figure 9. Areas where groundwater pumping by centrifugal pump was difficult, incorporating the spatial variation of PAT values less than $1 \mathrm{~m}$ (shaded area) with river levels during $(\mathbf{a}, \mathbf{b})$ non-seasonal pumping; (c,d) seasonal pumping, at $(\mathbf{a}, \mathbf{c})$ the Ipo Weir management level $(28 \mathrm{~m})$, and $(\mathbf{b}, \mathbf{d})$ at the minimum weir level $(25.3 \mathrm{~m})$.

During the seasonal pumping period, depletion began in the central $0.66 \mathrm{~km}^{2}$ area of the study site, where several groundwater pumping wells for water-curtain cultivation were located (Figure 9c); it expanded to $1.04 \mathrm{~km}^{2}$ after the weir was opened (Figure 9d). At this time, the number of depleted wells increased from 54 to 72 due to opening of the weir (Table 3). It was predicted that groundwater pumping rates would also decrease outside the depleted area because the operating abilities of the centrifugal pumps were significantly affected by groundwater drawdown.

In Figure 10, it can be seen how aquifer productivity was reduced after the weir was opened. Any area with API values of less than 0.8 can be regarded as being an area in which crop cultivation will be damaged due to decreased groundwater pumping rates. Specific capacity usually decreased near the river during the non-seasonal pumping period (Figure 10a), where the minimum API was estimated at 0.41, and 61 groundwater wells were contained in the area that had an API $\leq 0.8$ (Table 4). During the seasonal pumping period, this area expanded, with the minimum API reaching 0 in areas where numerous groundwater pumping wells for water-curtain cultivation were located (Figure 10b). At this time, the specific capacity of 234 groundwater pumping wells was reduced by $>20 \%$ (Table 4). Based on both PAT and API indexes, groundwater pumping rates in most of the study area decreased, which is expected to significantly reduce the thermal benefit applied to water-curtain greenhouses by groundwater pumping [39,40].

Table 4. Number of groundwater pumping wells experiencing difficulty due to the opening of the weir (API $\leq 0.8)$.

\begin{tabular}{|c|c|c|c|c|c|}
\hline \multirow[b]{2}{*}{ Period } & \multirow[b]{2}{*}{ Area $\left(\mathbf{k m}^{2}\right)$} & \multicolumn{4}{|c|}{ Number of Groundwater Pumping Wells (API $\leq \mathbf{0 . 8 )}$} \\
\hline & & $\begin{array}{l}\text { Centrifugal } \\
\text { Pump }\end{array}$ & $\begin{array}{c}\text { Underwater } \\
\text { Pump }\end{array}$ & $\begin{array}{l}\text { Unidentified } \\
\text { Pump Type }\end{array}$ & Total \\
\hline Non-seasonal pumping period & 0.48 & 7 & 54 & 0 & 61 \\
\hline Seasonal pumping period & 1.02 & 46 & 186 & 2 & 234 \\
\hline
\end{tabular}



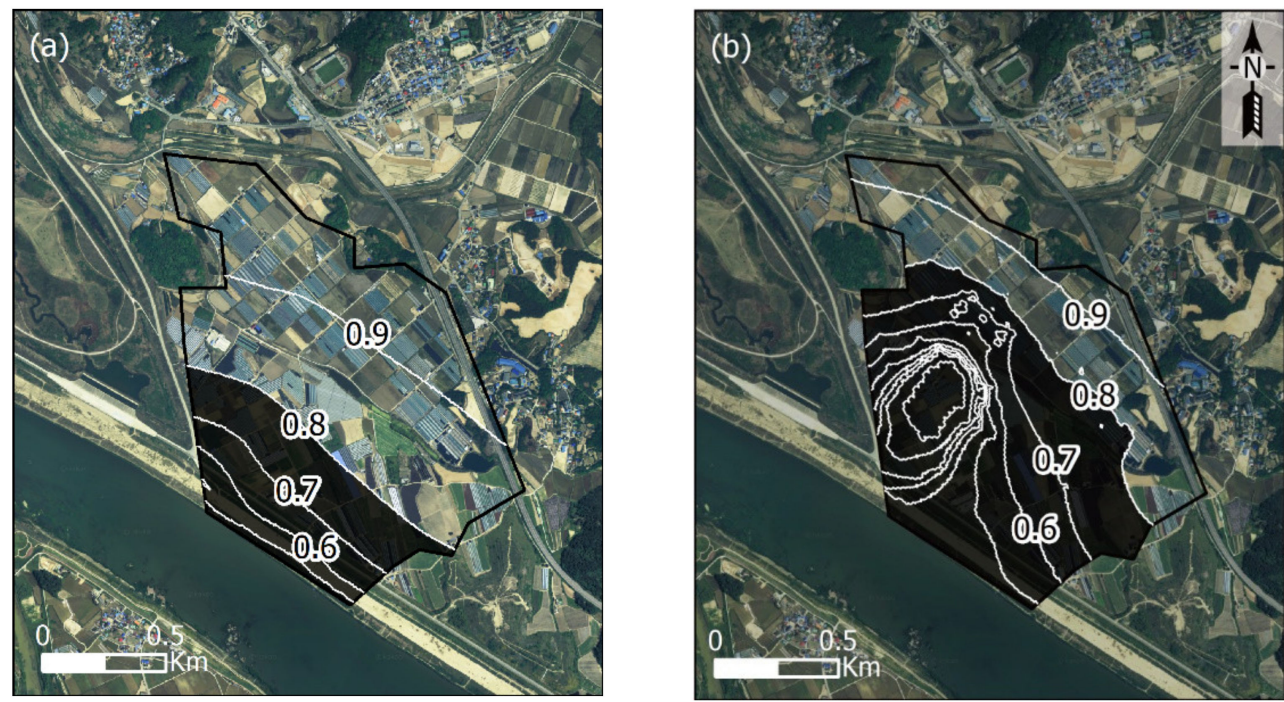

Figure 10. Areas in which aquifer productivity decreased due to opening of the weir, incorporating spatial variations of API values less than 0.8 (shaded area), during (a) non-seasonal and (b) seasonal pumping periods.

Water supply alternatives are needed if weirs are to be operated efficiently in areas concerned with difficult groundwater use. Countermeasures-which could include using alternative pumping wells, managed aquifer recharge (MAR), and surface water-should be established in the field by investigating groundwater levels and use.

Using alternative pumping wells, the most effective countermeasure, could restore the total amount of groundwater use levels before the opening of the weir, although the possibility of local groundwater depletion occurring in some areas cannot be ignored. Therefore, the sustainable development yield and the impact of alternative pumping wells on groundwater should be evaluated. The MAR option could lead to additional groundwater availability, especially in areas where the API has been significantly decreased due to the opening of the weir or areas where groundwater use has exceeded the sustainable development yield. Successful MAR, which requires feasibility evaluation, including identifying methods suited to regional hydrological characteristics, should be performed together with quantitative analysis of the managed aquifer recharge effect. Lastly, surface water can be used as an alternative water source in areas with groundwater depletion where alternative well development would be difficult.

\section{Summary and Conclusions}

Water-curtain cultivation areas are located mostly on alluvium near the four major rivers in South Korea, where groundwater levels can be directly influenced by river level variations, including those brought about by weir operations. The effect of Ipo Weir opening on stream-aquifer interactions and seasonal groundwater use have been analyzed using numerical simulations, and the resulting conclusions have been summarized below.

Our modeling predicted that opening of the weir led to changes in the stream-aquifer interaction with the groundwater flow system. A decline in river level due to opening of the weir led to groundwater drawdown, especially in areas where large amounts of groundwater were used. Changes in groundwater flow affected the hydrological conditions of the adjacent river tributary, decreasing groundwater discharge by $4 \%$, to the extent that its ecosystem could have been affected by the decreased river flows. In water-curtain cultivation areas, where the groundwater level is reduced below that of the river level, opening of the weir leads to a decrease in the induced groundwater recharge, increasing groundwater discharge by $30 \%$.

Opening of the weir had significant impacts on seasonal groundwater use for watercurtain cultivation. Groundwater pumping rates decreased with the change in the aquifer 
transmissivity caused by groundwater drawdown, and the areas where the groundwater could not be pumped increased during the seasonal pumping period. Locations where difficulty was experienced by groundwater users in operating centrifugal pumps were first seen in the central part of study area, while groundwater pumping rates by underwater pumps were affected by the largest magnitude near the river. The areas where the groundwater could not be accessed by centrifugal pumps increased by 1.6 times after opening the weir, and as a result, the depleted wells increased by 1.3 times. At this time, the specific capacity in wells, equivalent to $64 \%$ of all wells, was reduced by $20 \%$. Consequently, groundwater use was most likely affected in low transmissivity areas where the API decreased after the weir was opened, especially with respect to centrifugal pumps. The decreased groundwater pumping rates could also lower the thermal effect of water-curtain greenhouses in winter, thus reducing crop cultivation efficiency. This indicates that water supply alternatives such as alternative pumping wells, MAR, and surface water are needed so that the weirs can be operated efficiently and field requirements can be met, while the deleterious effects on groundwater can be avoided.

The results of this research can be useful to predict the changes to groundwater systems caused by seasonal pumping and opening of the weir in South Korean greenhouse cultivation areas, thus providing a means of establishing strategies for more efficient water resource management.

Author Contributions: Conceptualization, H.L., E.L., Y.K. and M.-H.K.; investigation, H.L., E.L. and S.-H.L.; data analysis, H.L.; methodology, H.L., E.L. and M.-H.K.; writing-original draft, H.L. and M.-H.K.; writing-review and editing, H.L., E.L., Y.K., S.-H.L. and M.-H.K.; project administration, Y.K.; supervision, Y.K. and M.-H.K. All authors have read and agreed to the published version of the manuscript.

Funding: This research was funded by Korea Ministry of Science and ICT (MSIT): Basic Research Project (GP2020-012) of the Korea Institute of Geoscience and Mineral Resources (KIGAM), and Korea Ministry of Environment (MOE): Research Project (IP2019-009).

Institutional Review Board Statement: Not applicable.

Informed Consent Statement: Not applicable.

Data Availability Statement: Not applicable.

Conflicts of Interest: The authors declare no conflict of interest.

\section{References}

1. Korea Institute of Geoscience and Mineral Resources. Report of Research on the Improvement Plan of Environment Friendly WaterCurtain Cultivation Area for Groundwater Conservation; Korea Institute of Geoscience and Mineral Resources: Daejeon, Korea, 2019. (In Korean)

2. Lee, H.; Koo, M.H.; Lim, J.; Yoo, B.H.; Kim, Y. Impacts of seasonal pumping on stream depletion. J. Soil Groundw. Environ. 2016, 21, 61-71. (In Korean with English abstract) [CrossRef]

3. Cho, B.W.; Yun, U.; Lee, B.D.; Ko, K.S. Hydrogeological characteristics of the Wangjeon-ri PCWC area, Nonsan-city, with an emphasis on water level variations. J. Eng. Geol. 2012, 22, 195-205. (In Korean with English abstract) [CrossRef]

4. Lee, H.; Koo, M.H.; Kim, Y. Impacts of seasonal pumping on stream-aquifer interactions in Miryang, Korea. Groundwater 2017, 55, 906-916. [CrossRef] [PubMed]

5. Kwon, H.I.; Koh, D.C.; Jung, B.; Ha, K. Quantification of seasonally variable water flux between aquifer and stream in the riparian zones with water curtain cultivation activities using numerical simulation. J. Geol. Soc. Kor. 2017, 53, $277-290$.

6. Madlala, T.; Kanyerere, T.; Oberholster, P.; Xu, Y. Application of multi-method approach to assess groundwater-Surface water interactions, for catchment management. Int. J. Environ. Sci. Technol. 2019, 16, 2215-2230. [CrossRef]

7. Flores, L.; Bailey, R.T.; Kraeger-Rovey, C. Analyzing the effects of groundwater pumping on an urban stream-aquifer system. JAWRA J. Am. Water Resourc. Assoc. 2020, 56, 310-322. [CrossRef]

8. Lee, H.; Koo, M.H.; Kim, K.; Kim, Y. Spatio-Temporal Variations in Stream-Aquifer Interactions Following Construction of Weirs in Korea. Groundwater 2016, 54, 448-458. [CrossRef]

9. Oh, Y.Y.; Hamm, S.Y.; Kim, G.B.; Lee, C.M.; Chung, S.Y. Statistical Approach to River-Aquifer Interaction in the Lower Nakdong River Basin, Republic of Korea. Irrig. Drain. 2016, 65, 36-47. [CrossRef] 
10. Kim, G.B.; Cha, E.J.; Jeong, H.G.; Shin, K.H. Comparison of time series of alluvial groundwater levels before and after barrage construction on the lower Nakdong River. J. Eng. Geol. 2013, 23, 105-115. (in Korean with English abstract) [CrossRef]

11. Ahn, J.M.; Lee, S.; Kang, T. Evaluation of dams and weirs operating for water resource management of the Geum River. Sci. Total Environ. 2014, 478, 103-115. [CrossRef]

12. Levitt, D.G.; Newell, D.L.; Stone, W.J.; Wykoff, D.S. Surface water-Groundwater connection at the Los Alamos Canyon weir site: Part 1. Monitoring site installation and tracer tests. Vadose Zone J. 2005, 4, 708-717. [CrossRef]

13. Krause, S.; Bronstert, A.; Zehe, E. Groundwater-surface water interactions in a North German lowland floodplain-Implications for the river discharge dynamics and riparian water balance. J. Hydrol. 2007, 347, 404-417. [CrossRef]

14. Kim, S.; Chung, S.; Park, H.; Cho, Y.; Lee, H. Analysis of environmental factors associated with cyanobacterial dominance after river weir installation. Water 2019, 11, 1163. [CrossRef]

15. Lee, S.J.; An, K.G. Influence of Weir Construction on Chemical Water Quality, Physical Habitat, and Biological Integrity of Fish in the Geum River, South Korea. Pol. J. Environ. Stud. 2019, 28, 2175-2186. [CrossRef]

16. Choi, H.S. Effect on water quality and fish habitat improvement of Wonju Cheon by instream flow increasing. J. Wetl. Res. 2008, 10, 57-68. (In Korean)

17. Lee, J.; Lee, Y.; Woo, S.; Kim, W.; Kim, S. Evaluation of water quality interaction by dam and weir operation using SWAT in the Nakdong River Basin of South Korea. Sustainability 2020, 12, 6845. [CrossRef]

18. Koo, M.H.; Kim, J.W. Impacts of weir opening in Four Major Rivers on agricultural groundwater use. In Proceedings of the Korean Society of Agricultural Engineers Conference, Hongcheon-gun, Korea, 10 October 2019; p. 282. (In Korean)

19. Oh, J.O.; Lee, J.J.; Jun, S.M. A Study on Groundwater Level Fluctuation in Surroundings by Operational Water Level of HapcheonChangnyeong Weir. Crisisonomy 2020, 16, 29-39. (In Korean with English abstract) [CrossRef]

20. Lee, H.; Koo, M.H.; Lee, J.; Kim, K. Changes in Stream-Aquifer Interactions Due to Gate Opening of the Juksan Weir in Korea. Water 2021, 13, 1639. [CrossRef]

21. Korea Water Resources Corporation. Groundwater Basic Survey Report of Yeoju Area; Korea Water Resources Corporation: Daejeon, Korea, 2015. (In Korean)

22. Ministry of Land, Transport and Maritime Affairs. River Basic Plan of Han River; Ministry of Land, Transport and Maritime Affairs: Sejong, Korea, 2011. (In Korean)

23. Korea Institute of Geoscience and Mineral Resources Korea. 1:50,000 Geological Report of the Ipo Sheet; Korea Institute of Geoscience and Mineral Resources Korea: Daejeon, Korea, 1989. (In Korean)

24. Korea Water Resources Corporation. Report of Development of Groundwater Flow Model and Standardization of Water Supply Alternatives in Han and Yeongsan River Basins; Korea Water Resources Corporation: Daejeon, Korea, 2019. (In Korean)

25. Jeon, S.K.; Koo, M.H.; Kim, Y.; Kang, I.O. Statistical analysis of aquifer characteristics using pumping test data of national groundwater monitoring wells for Korea. J. Soil Groundw. Environ. 2005, 10, 32-44. (In Korean with English abstract)

26. Jenkins, C.T. Computation of Rate and Volume of Stream Depletion by Wells; U.S.G.S.: Arlington, VA, USA, 1968 ; p. 17.

27. Koo, M.H.; Lee, D.H. A numerical analysis of the water level fluctuation method for quantifying groundwater recharge. J. Geol. Soc. Korea 2002, 38, 407-420. (In Korean)

28. Ministry of Land, Infrastructure and Transport. Performance Guidelines for Groundwater; Ministry of Land, Infrastructure and Transport: Sejong, Korea, 2015. (In Korean)

29. Korea Water Resources Corporation. Groundwater Annual Report; Korea Water Resources Corporation: Daejeon, Korea, 2018. (In Korean)

30. Korea Institute of Geoscience and Mineral Resources. Research Report of Advancement in the Utilization of Waterside Groundwater; Korea Institute of Geoscience and Mineral Resources: Daejeon, Korea, 2012. (In Korean)

31. Waterloo Hydrogeologic. Visual MODFLOW Premium 4.2 User's Manual; Waterloo Hydrogeologic: Waterloo, ON, Canada, 2006.

32. Stefania, G.A.; Rotiroti, M.; Fumagalli, L.; Simonetto, F.; Capodaglio, P.; Zanotti, C.; Bonomi, T. Modeling groundwater/surfacewater interactions in an Alpine valley (the Aosta Plain, NW Italy): The effect of groundwater abstraction on surface-water resources. Hydrogeol. J. 2018, 26, 147-162. [CrossRef]

33. Zhang, D.; Han, D.; Song, X. Impacts of the Sanmenxia dam on the interaction between surface water and groundwater in the lower Weihe River of Yellow River watershed. Water 2020, 12, 1671. [CrossRef]

34. Matula, S.; Mekonnen, G.B.; Bát'ková, K.; Nešetřil, K. Simulations of groundwater-surface water interaction and particle movement due to the effect of weir construction in the sub-watershed of the river Labe in the town of Děćín. Environ. Monit. Assess. 2014, 186, 7755-7770. [CrossRef] [PubMed]

35. Conant, J.B.; Robinson, C.E.; Hinton, M.J.; Russell, H.A. A framework for conceptualizing groundwater-surface water interactions and identifying potential impacts on water quality, water quantity, and ecosystems. J. Hydrol. 2019, 574, 609-627. [CrossRef]

36. Hillel, N.; Wine, M.L.; Laronne, J.B.; Licha, T.; Be'eri-Shlevin, Y.; Siebert, C. Identifying spatiotemporal variations in groundwatersurface water interactions using shallow pore water chemistry in the Lower Jordan River. Adv. Water Resour. 2019, 131, 103388. [CrossRef]

37. Thin, K.C.; Khaing, M.M.; Aye, K.M. Design and performance analysis of centrifugal pump. World Acad. Sci. Eng. Technol. 2008, 46, 422-429. 
38. Rakibuzzaman, M.; Suh, S.H.; Kim, K.W.; Kim, H.H.; Cho, M.T.; Yoon, I.S. A study on multistage centrifugal pump performance characteristics for variable speed drive system. Procedia Eng. 2015, 105, 270-275. [CrossRef]

39. Meneses, J.F.; Canham, A.E. A water-curtain heating system for plastic greenhouses. J. Agric. Engin. Res. 1992, 52, 193-200. [CrossRef]

40. Kim, H.K.; Kim, Y.S.; Jeon, J.G.; Paek, Y.; Lee, J.H.; Khoshimkhujaev, B.; Kim, Y.C. Evaluation of optimal water flow and temperature in response to outdoor air temperature in plastic greenhouse with recirculated water curtain system. J. Mech. Sci. Technol. 2017, 31, 3043-3051. [CrossRef] 